\title{
A importância da educação socioemocional no processo de ensino e aprendizagem desenvolvidos no "programa líder em mim" da escola de Ensino Fundamental Batista
}

The importance of socioemotional education in the teaching and learning process developed in the "leader in me" program of the Baptist fundamental school

\begin{abstract}
Resumo: O presente artigo visa apresentar uma reflexão a respeito da importância da educação socioemocional no processo de ensino e aprendizagem, o Programa Educacional de Liderança, com foco na prática pedagógica e intencionalidade formativa e humanizadora, tendo a instituição escolar como influenciadora e como um espaço de sua efetivação, contribuindo com a formação dos sujeitos nos processos de escolarização. Este trabalho tem por objetivo mostrar a importância de uma prática educativa mais humanizada capaz de emancipar, libertar e direcionar o ser humano para o despertar de uma nova consciência própria, tornando-o assim um cidadão mais reflexivo e crítico, onde se tornará parte do próprio processo educativo e consequentemente de sua história. As reflexões aqui apresentadas resultam de uma pesquisa realizada em uma escola de ensino fundamental da cidade de Santa Maria no RS. A partir dos conceitos teóricos de Paulo Freire tais conceitos trazem elementos que contribuem para a construção de aprendizagens que têm como horizonte a humanização dos sujeitos. Essas concepções se materializam em atitudes, escolhas e relações empreendidas na prática educativa em que os (as) estudantes são compreendidos como seres sociais e históricos, que ao se desenvolverem por meio do diálogo, a percepção crítica sobre a realidade, vão se tornando capazes de produzir seus próprios saberes e de criar condições para uma atuação mais efetiva na sociedade.
\end{abstract}

Palavras chave: Educação; socioemocional; humanização; liderança.

Abstract: This article aims to present a reflection about the importance of socioemotional education in the teaching and learning process, the Educational Leadership Program, focusing on pedagogical practice and formative and humanizing intentionality, with the school institution as an influencer and as a space effectiveness, contributing to the formation of subjects in the schooling processes. This work aims to show the importance of a more humanized educational practice capable of emancipating, liberating and directing the human being to awaken a new selfawareness, thus making him a more reflective and critical citizen, where he will become part of his own educational process and consequently its history. The reflections presented here are the result of a research carried out in an elementary school in the city of Santa Maria, RS. Based on Paulo Freire's theoretical concepts, these concepts bring elements that contribute to the construction of learning that has the humanization of subjects as a horizon. These conceptions are materialized in attitudes, choices and relationships undertaken in educational practice in which students are understood as social and historical beings, who, as they develop through dialogue, the critical perception of reality, become capable of produce their own knowledge and create conditions for a more effective performance in society. 
Keywords: Education; socioemotional; Humanization; leadership

\section{Introdução}

Nos últimos tempos nossa sociedade vem sendo marcada por transformação e rupturas no modelo de vida, principalmente no que está relacionado às relações de trabalho, cotidiano, vida familiar e ambiente escolar. Vivemos tempos de profunda e aceleradas mudanças na sociedade. Tudo muda muito rapidamente; "informações propagam-se à velocidade da luz". (ABED, 2014) as relações com o conhecimento e entre as pessoas estão marcadas pelo universo digital em que estamos mergulhados.

Diante desse cenário, o psicólogo norte-americano Howard Gardner, corrobora com sua Teoria das Inteligências Múltiplas, na qual defende que a educação seja um espaço para formação de bons cidadãos e bons trabalhadores, engajados na promoção do bem-estar da sociedade. Para ele, a sociedade contemporânea exige o fortalecimento da ética, do comprometimento e da excelência.

Nessa perspectiva está sendo implementada no Brasil a Base Nacional Comum Curricular (BNCC), que provavelmente vai acarretar uma grande mudança dos currículos escolares no país. Um dos pontos é o fato de a Base estabelecer, como dez competências fundamentais, competências socioemocionais. A partir do ano de 2020 , todas as escolas brasileiras terão de incluir as habilidades socioemocionais nos seus currículos. Ou seja, haverá a necessidade de adaptar os programas escolares e treinar os professores para que possam ministrar essas novas competências, que tem foco em habilidades não cognitivas, muito mais relacionadas ao comportamento e à administração das próprias emoções, mas que impactam positivamente o indivíduo e a relação dele com o mundo ao seu redor.

Nesta perspectiva, entende-se a educação socioemocional como um o processo do qual os alunos aprendem, dentro do currículo escolar a refletir e efetivamente aplicar conhecimentos e atitudes necessários ao longo da vida escolar, educando os corações, inspirando mentes, materializando projetos e contribuindo para a transformação desses estudantes pela educação. 
Segundo Pamela (2018), os pilares que apoiam a educação socioemocional incluem autoconhecimento, autogerenciamento, tomada de decisões, habilidades de relacionamentos e consciência social. Para Gama (1998) somos dotados de graus variados de cada uma das inteligências e maneiras diferentes com que elas se combinam, organizam e se utilizam dessas capacidades intelectuais para resolver problemas e criar produtos, para o qual será sempre essencial utilizar diferentes inteligências e, principalmente mesclá-las nas tarefas a fim de alcançar um objetivo. Aprender a lidar com as emoções, agregando valores, na atual proposta do currículo da educação é a proposta desse artigo, "pois educar as emoções com a finalidade de tornar os estudantes mais conscientes e participativos dentro da realidade ao qual vivem" é de fundamental importância.

A partir de Paulo Freire (2009), tais conceitos trazem elementos que contribuem para a construção de aprendizagens que têm como horizonte a humanização dos sujeitos. Essas concepções se materializam em atitudes, escolhas e relações empreendidas na prática educativa em que os (as) estudantes são compreendidos como seres sociais e históricos, que ao se desenvolverem por meio do diálogo, a percepção crítica sobre a realidade, vão se tornando capazes de produzir seus próprios saberes e de criar condições para uma atuação mais efetiva na sociedade.

A principal função da escola é também ensinar habilidades socioemocionais. É lá que o aluno deve aprender a se relacionar com as pessoas, a ser tolerante e a conviver com as diferenças. A partir de tais considerações o presente estudo objetiva mostrar a importância de uma prática educativa mais humanizada capaz de emancipar, libertar e direcionar o ser humano para o despertar de uma nova consciência própria, tornando-o assim um cidadão mais reflexivo e crítico, onde este se tornará parte do próprio processo educativo e consequentemente da sua história.

A Escola de Ensino Fundamental Batista vem contribuindo para a educação brasileira com bastante intensidade. A semeadura foi fértil, embora tenha iniciado de modo simples e com muita humildade. "Assim nascem as 
grandes obras: medram, vicejam crescem e permanecem, porque alimentadas por grandes ideais, porque sustentadas por grandes personalidades".

\section{Aspectos históricos e caracterização da escola}

A história da escola começa em 18 de fevereiro de 1957, em uma Assembleia Geral da Convenção das Igrejas Batistas Independentes, realizada na cidade de Rio Grande- RS. Foi proposta a criação de uma Casa Editora Batista Independente, que, mais tarde, transformou-se na Sociedade Educacional Beneficente Batista Independente, atual Mantenedora.

Em 11 de março de 1961, a "Escola Paulo de Tarso" instalou-se na cidade de Santa Maria, no bairro Salgado Filho, com um pequeno prédio de madeira. A partir de 1963, a escola passou a oferecer também o ensino fundamental completo. No ano de 2007, a Instituição passa a se chamar "Escola Batista", como é conhecida hoje. Ao longo de toda história momentos difíceis aconteceram, mas, muito se tem a comemorar. Foram esses momentos, bons e ruins, que fizeram a escola crescer e tornar-se referência em muitos aspectos.

Atualmente, a escola oferece desde a Educação Infantil aos Anos Finais do Ensino Fundamental. Com aproximadamente 500 alunos, busca oferecer um ensino de qualidade, tanto no aspecto de patrimônio e infraestrutura, como de qualificação dos profissionais, que são responsáveis por coordenar, o processo de ensino e aprendizagem dos educandos. Visando uma melhor formação pessoal, desde 2017, a escola trabalha com o Programa "O Líder em Mim", que tem como objetivo desenvolver as competências socioemocionais dos educandos.

Apostando e acreditando, que já não basta mais a escola apenas preparar o aluno para níveis mais elevados da escolaridade, uma vez que o que ele precisa é aprender para compreender a vida, a si mesmo e a sociedade, exercendo a cidadania, a Gestão Pedagógica juntamente com a mantenedora da Escola Batista, proporciona aos seus educandos a oportunidade de vivências dos sete hábitos trabalhando sobre os paradigmas mentais através do Programa "O Líder em Mim". 
O Programa incentiva os alunos a acharem seus próprios dons e enxerga que cada criança é um líder em potencial. O método é um processo escolar. Começa com os professores aprendendo os valores de um líder e passando para as crianças, que aprendem responsabilidades como balancear corpo, mente e espírito. Assim como aprendem a resolver problemas matemáticos, também precisam aprender a lidar com outras pessoas. Diante desta perspectiva, surgem novos desafios na instituição, para os gestores, pais, alunos e professores.

Quando o gestor abre espaço para que a comunidade participe, esta última acaba tendo responsabilidade com a tomada de decisões iniciadas pela escola, possibilitando que todos os membros, sejam eles pais ou funcionários, se sintam importantes no fazer da educação, abrangendo novas metas.

\section{Resultados e discussões}

\section{Descrição da Experiência do Programa "Líder em Mim"}

Os dados apresentados nesse estudo são oriundos do portfólio construído pelas professoras e coordenadora da Ed. Infantil e, tem por objetivo apresentar os trabalhos do programa "Líder em Mim" que são realizados desde o ano de 2016 na Escola Batista de Santa Maria, da Educação Infantil até o $4^{\circ}$ ano do Ensino Fundamental. Os planos implementados são documentados no Portfólio. Isso permite que não somente seja verificado o progresso, mas também celebrem e compartilhem seus resultados.

Segundo Villas Boas (2001) "o portfólio é um procedimento de avaliação que permite aos alunos participar da formulação dos objetivos de sua aprendizagem e avaliar seu progresso. Eles são, portanto, participantes ativos da avaliação, selecionando as melhores amostras de seu trabalho para incluílas no portfólio".

Referente ao paradigma da liderança na escola, Bento, Ribeiro e Telles (2010:3) concebem a liderança "perspectiva através de líderes formais e informais que têm como objetivo a melhoria permanente das organizações escolares, promovendo o desenvolvimento das estratégias para que, 
internamente nas instituições escolares, possam ir resolvendo com autonomia, os seus próprios problemas".

Afonso (2011:85) declara que " a liderança é um processo repleto de emoções e o líder que consiga regular as suas próprias emoções e saiba ser empático será um líder mais eficaz". Podemos concluir que, em relação aos conflitos sociais e tensões dentro da escola, se torna essencial uma gestão eficaz para responder as necessidades da escola.

A Equipe Farol da Escola Batista foi construída para acrescentar nos objetivos do programa "O Líder em Mim" e partindo da união de todos, pensar e implementar atividades que proporcionam um ambiente de liderança na escola, principalmente por meio do envolvimento dos alunos. A equipe Farol coordena iniciativas específicas para cada grupo de interessados (funcionários, alunos, pais e comunidade) na escola, deve ser permanente, se reunir com regularidade e supervisionar a implementação do modelo de liderança em toda a escola.

O Programa oferece capacitações para os colaboradores da escola. Essas capacitações possuem o propósito de refletir sobre práticas e possibilidades de intervenção na busca pela formação de líderes na escola, além de buscar metas e organizar estratégias de aplicação durante o ano letivo a iniciar.

Sem dúvida, servir de modelo é a forma mais importante de ensinar. Independentemente do que os adultos falam, eles devem fazer o que dizem. Dar o exemplo permite que os adultos ensinem os alunos, desde o momento que entram na escola até o momento que saem. Apesar de todos os professores estarem preparados para ter o impacto mais direto, os administradores e o pessoal de apoio também têm a oportunidade de reforçar a liderança em suas interações com os alunos. Capacitar todos os adultos trará diversos e contínuos benefícios aos alunos.

Dentro das competências socioemocionais tratadas pela BNCC (2018), a empatia e cooperação surgem como valores diretamente ligados ao respeito. Inegavelmente ao exercitar a empatia, o diálogo, a resolução de conflitos e a cooperação, conseguimos promover o respeito ao próximo. 
Dentro da proposta de tornar os educandos líderes, o "Líder em Mim", dentro de suas estratégias propostas, trabalha com conceitos importantes para a formação dos pequenos, entre elas o respeito e a empatia. Na escola, o sinal de levantar a mão para pedir silêncio, mostra o quanto precisamos prestar atenção em quem está falando e respeitar o uso da palavra do outro. Através do Programa as professoras trabalham com os alunos, da ed. Infantil ao quarto ano, essa atitude de levantar a mão quando necessitam falar e serem ouvidas. Imediatamente os alunos ao perceberem esse gesto ficam em silêncio em sinal de respeito e atenção. A formação dos líderes se dá de dentro para fora, assim como o crescimento de uma árvore e, por isso, a construção da "Arvore dos Sete Hábitos" conforme mostra a figura 1 é pensada e executada com a ajuda mútua dos educandos.

Figura 1 - Arvore dos Sete Hábitos

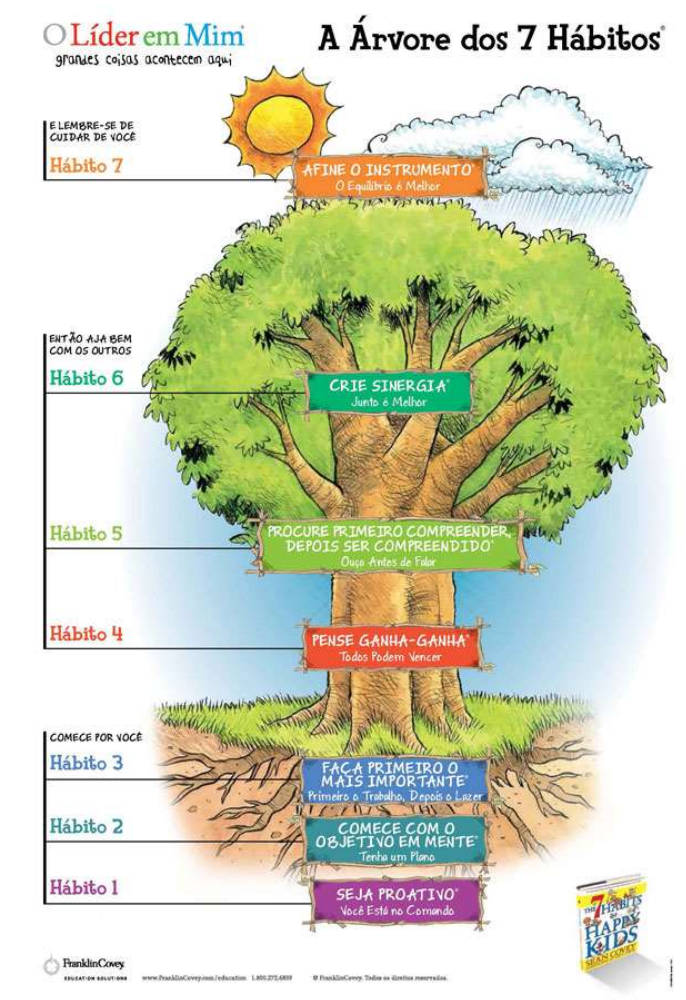

Fonte: Portfólio das Atividades desenvolvidas do OLEM -2017- Escola Batista SM- RS

O programa "Líder em Mim" trabalha com a vivência dos 7 hábitos e a quebra de paradigmas, cujos resultados se relacionam diretamente com os 5 domínios das competências socioemocionais: Consciência, estabilidade 
emocional, abertura a novas experiências, amabilidade e extroversão. A principal finalidade do ensino dos hábitos é preparar os estudantes para lidar com a vida. É ajudá-los a se tornar capazes de contar consigo mesmos (independência) e a trabalhar bem com as outras pessoas (interdependência). É ajudá-los a progredir como alunos, como pais, como integrantes da futura força de trabalho e como cidadãos de uma comunidade. E os hábitos não são apenas para uso num futuro distante: são para serem usados hoje. Ensinar os hábitos não é uma atividade para ser realizada uma só vez. Não é uma aula única. É uma jornada contínua de progresso, que acontece de dentro para fora.

Os alunos da Ed. Infantil ao quarto ano participaram da montagem da Árvore dos 7 hábitos, atividade que reuniu estudantes e equipe pedagógica em um só objetivo, o trabalho em conjunto com muita sinergia e um objetivo em mente. A árvore representa os sete hábitos e a importância de cada um deles no processo de aprendizagem. A seguir serão apresentadas as atividades desenvolvidas no Programa Líder em Mim baseadas nos 7 Hábitos:

\section{Releitura da árvore dos 7 hábitos: 0 objetivo era reproduzir a partir do olhar do aluno.}

Figura 2. Árvore dos sete hábitos confeccionada pelos alunos do primeiro ano do ensino fundamental.

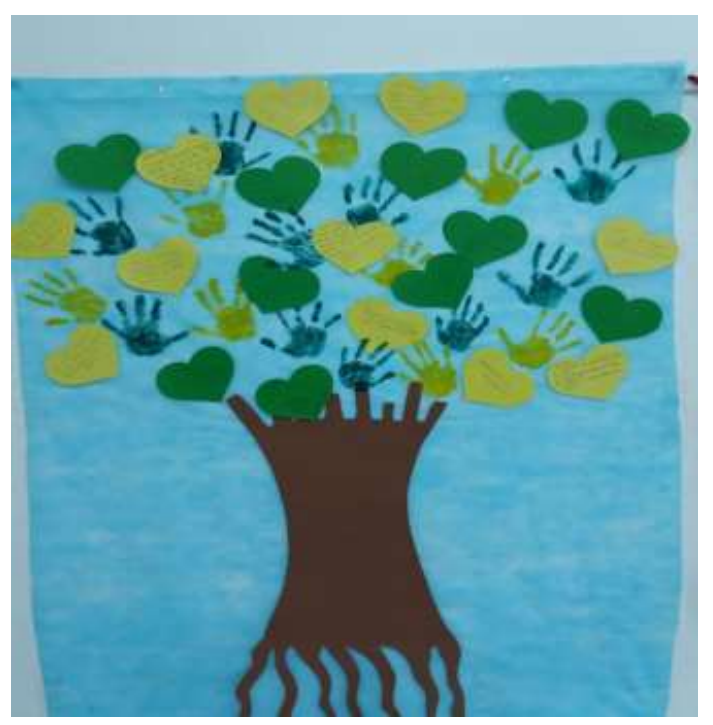

Fonte: Portfólio - Acervo Escola Batista. 
As metas traçadas pelo programa vão desde a Gestão, com metas amplas para toda a escola, até as salas de aula. Além disso, cada educando escolhe sua meta pessoal e ajuda na escolha na escolha da meta da turma. Cada vez que sua meta é atingida, deve haver uma comemoração, para que as conquistas sejam valorizadas por todos. A escola propõe metas solidárias, para que todos entendam o propósito da empatia e de fazer o bem a outra pessoa. No ano de 2018 , as turmas do quarto ano aprenderam a fazer tricô e, juntando cada confecção, fizeram cobertas para doação.

Os sete hábitos, propostos pelo programa, são desenvolvidos diariamente nas salas de aula e na escola como um todo. Para que as atitudes e ações sejam eficazes é preciso que a escola seja integralmente preparada para isso. Portanto, é preciso que todos estejam alinhados com o programa, buscando o mesmo objetivo: tornar-se líderes e responsáveis.

Ao longo do ano de 2017, foram realizadas diferentes propostas para que os educandos se envolvam nesse processo de formação de líderes. É importante que eles saibam quais objetivos a escola tem para eles. Para isso, além das metas as turmas e os educandos executam missões a cumprir, com o intuito de fazer com que os educandos se tornem responsáveis por suas ações, buscando melhorar a cada dia. As missões também são escolhidas em conjunto com as crianças, para que elas entendam a importância da proposta, mostradas na figura 3 .

Figura 3 . Registro da atividade

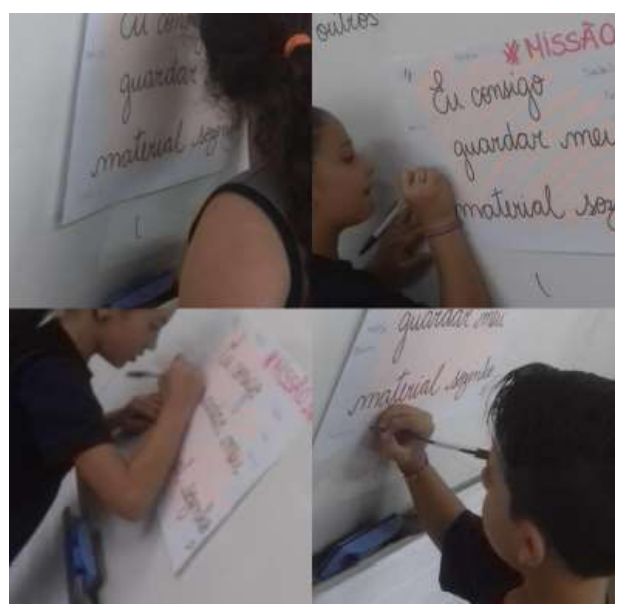

Fonte: Portfólio - Acervo Escola Batista. 
Outro aspecto que o programa trabalha, dentro da responsabilidade, é da importância de cuidar da escola, do ambiente escolar, desde sua estrutura física até as relações interpessoais. Para mostrar o quanto isso é importante, a turma do Turno Integral, de 2018, organizava a sala de leitura, na biblioteca da escola, separando os livros por temáticas.

As metas traçadas pelo programa vão desde a Gestão, com metas amplas para toda a escola, até as salas de aula. Além disso, cada educando escolhe sua meta pessoal e ajuda na escolha na escolha da meta da turma. Cada vez que sua meta é atingida, deve haver uma comemoração, para que as conquistas sejam valorizadas por todos. A escola propõe metas solidárias, para que todos entendam o propósito da empatia e de fazer o bem a outra pessoa. Em 2018, as turmas do quarto ano aprenderam a fazer tricô e, juntando cada confecção, fizeram cobertas para doação. Com essas atitudes solidárias percebemos que os alunos não são mais os mesmos, por meio do desenvolvimento de competências e habilidades relacionadas ao emocional na escola, os alunos conseguem construir uma sociedade mais justa e igualitária. Porém, é necessário ir além do currículo, desenvolvendo as competências no dia a dia da escola.

Figura 4. HÁBITO 1: SEJA PROATIVO- Responsabilidade, iniciativa e autoconfiança.

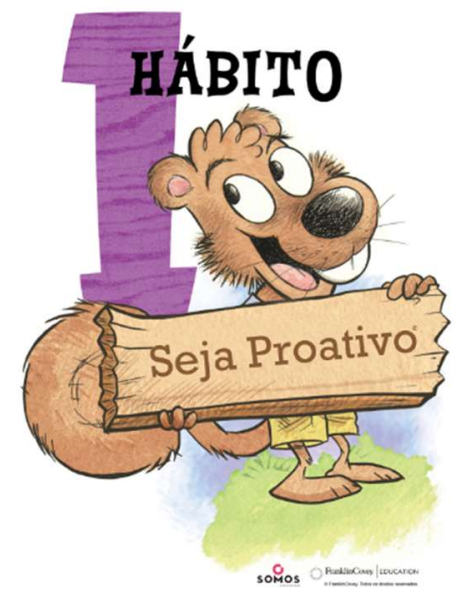

Fonte: Portfólio-OLEM

Atividade-Hora do Conto - Os alunos do primeiro ano ( $\mathrm{T}: 101)$ adoraram ouvir a história "Cascuda, a tartaruga proativa", que falava sobre os 7 hábitos trabalhados no OLEM (o Líder em Mim). Para fica mais divertido e criativo, os 
alunos confeccionaram tartarugas utilizando fundo de garrafa pet. Foi uma tarde muito animada e de muito aprendizado.

Atividade- Dia das mães - Uma turma do terceiro ano do ensino fundamental produziu juntamente com suas mães uma atividade artística que, logo a seguir, foram servidas pelos seus filhos, com um gostoso chá. (Proatividade).

Atividade- Proativo X Reativo-Alunos do quarto ano (401) debateram e refletiram sobre o hábito 1. A diferença entre ser proativo e reativo. Evidenciaram que para cada ação existe uma reação e consequentemente a responsabilidade sobre elas.

Figura 5. HÁBITO 2: COMECE COM O OBJETIVO EM MENTE: Visão, planejamento, estabelecimento de metas.

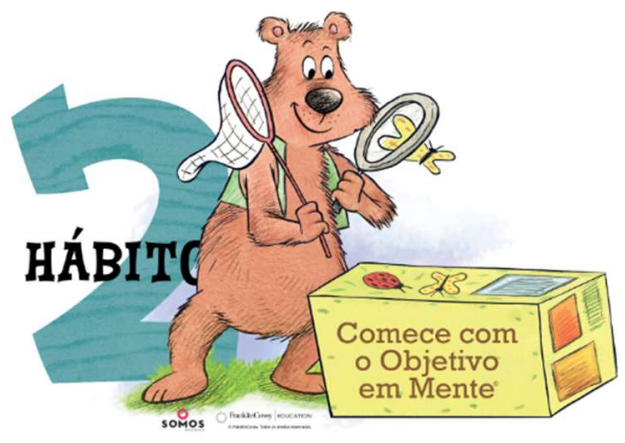

Fonte: Portfólio OLEM

Atividade: Comece com o objetivo em mente para a construção de doces de Páscoa. Os alunos da ed. Infantil (nível B), produziram gostosos biscoitos e brigadeiros. A produção envolveu a reflexão e discussão sobre as preferências, ingredientes, modo de fazer e finalmente a alegria em produzir as guloseimas.

Atividade: As turmas do primeiro ano do ensino fundamental começaram com um objetivo em mente, com a meta de arrecadar mil balas, para serem doadas, posteriormente para uma instituição de caridade. A meta foi cumprida com sucesso, foram arrecadadas 2.517 balas e entregues à Escola de Educação Infantil Borges de Medeiros. 
Figura 6. HÁBITO 3: FAÇA PRIMEIRO O MAIS IMPORTANTE- Organização, administração do tempo.

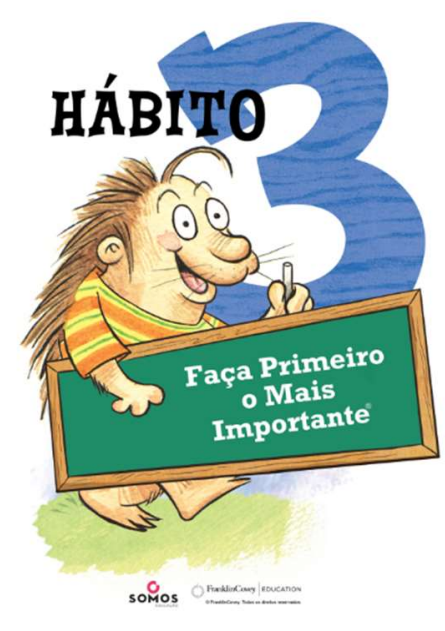

Fonte: Portfólio - OLEM

Atividade: Para trabalhar o hábito 3, "Faça primeiro o mais importante", alunos da turma 101 planejaram, juntamente com a família, as tarefas semanais de cada um, considerando as mais importantes. Atividade: A turma 102 aprofundou seus conhecimentos sobre o hábito 3, "Faça primeiro o mais importante", com a confecção de um crachá, que será utilizado pelos alunos sempre que estiverem realizando a tarefa mais importante do dia. Nele está escrito: "Não me interrompa, estou fazendo o mais importante". Atividade: Primeiro o mais importante- Alunos da turma do quarto ano do ensino fundamental associaram os estudos sobre as horas ao hábito 3 . Comece primeiro com o mais importante. Assim tendo conhecimento sobre as horas fica mais fácil organizar sua agenda após eleger as prioridades.

Para trabalhar o hábito 3, "faça primeiro o mais importante", as turmas do terceiro ano aprenderam sobre o Haikai (figura 7), pequeno verso feito com cinco sílabas na primeira linha, sete sílabas na segunda linha e cinco sílabas na última linha. A proposta exigiu a participação de 30 alunos de uma turma do terceiro ano do ensino fundamental, na qual realizaram uma reflexão do que era mais importante na hora de criar o verso. Os alunos leram o que alguns autores e outros alunos que já escreveram, para se familiarizar com a forma reduzida desse tipo de poema. Tendo em mente que a proposta do haicai é ser breve, trabalharam com a habilidade de descrição, de maneira objetiva, 
sintética e precisa. Ao final da atividade cada aluno comentou sua participação e atribuiu a si mesmo uma avaliação final. Essa avaliação serviu também para uma reflexão sobre o envolvimento na atividade.

Figura 7. Atividade De Haikai

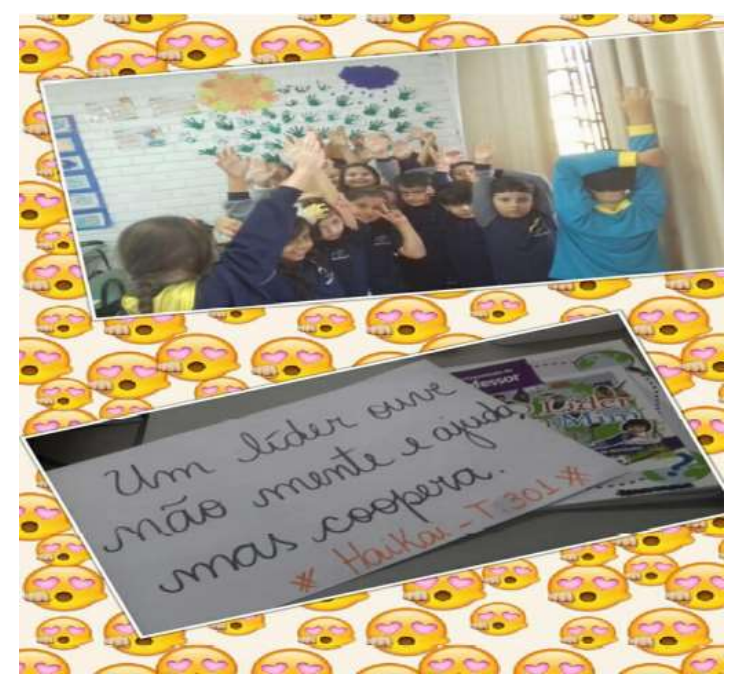

Fonte: Portfólio - Acervo Escola Batista.

No hábito 4, "pense ganha-ganha", a proposta é trabalhar a importância de todos serem vitoriosos, ao serem empáticos e ouvirem o outro. Para isso, os educandos fizeram um "Chocolate Amigo", onde houve troca de doces entre os pequenos do primeiro ano (total de 20 alunos). A atividade foi planejada pela professora juntamente com as crianças. Uma festa interna de grande valor emocional para as crianças, onde foi trabalhado valores importantes como: amizade, respeito, ética, construção de relacionamento. A atividade foi concluída com muita alegria, surpresa e sucesso.

Figura 8. HÁBITO 4: PENSE GANHA- GANHA: Ética, respeito mútuo.

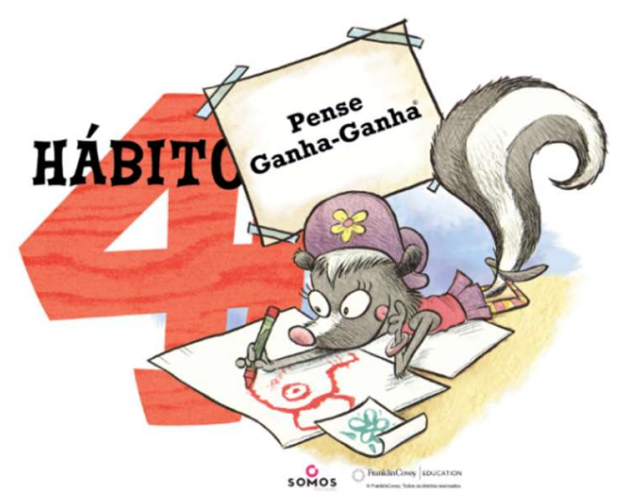

Fonte: Portfólio OLEM 
Atividade- A Natureza pede Ganha- Ganha- Aproveitando a semana do meio ambiente, as turmas do segundo ano do ensino fudamental, juntamente com as professoras da classe, estudaram sobre os tipos de solos e plantas. Para concretizar esses estudos, as turmas montaram uma horta suspensa. A atividade foi intitulada como "A natureza pede ganha-ganha" (figura 8).

Atividade- Massagem Ganha-Ganha-Teve atividade de ganha-ganha na turma 102. Os alunos e a professora da turma, adoraram receber massagem. Para relaxar, todos fizeram massagem e receberam, ao mesmo tempo.

Atividade: Diagrama de Lótus- Integrando o hábito 4-- Pense GanhaGanha e o Diagrama de Lótus, também proposto pelo OLEM e que permite o planejamento e exploração de ideias, uma turma do terceiro ano, esquematizou com ajuda da professora um lanche coletivo. Contando com a ajuda das famílias, os lanches individuais se tornaram um grande lanche para todos. Assim, todos saíram ganhando com a oportunidade de compartilhar o que haviam trazido.

Outra atividade realizada para trabalhar o hábito 4, foi a proposta dos 3 RS - reciclar, reduzir e reutilizar (figura 8), com o intuito de cuidar do meio ambiente. Os alunos refletem e pensam em alternativas para cuidar do planeta.

Figura 8. A proposta dos $3 \mathrm{RS}$ - reciclar, reduzir e reutilizar

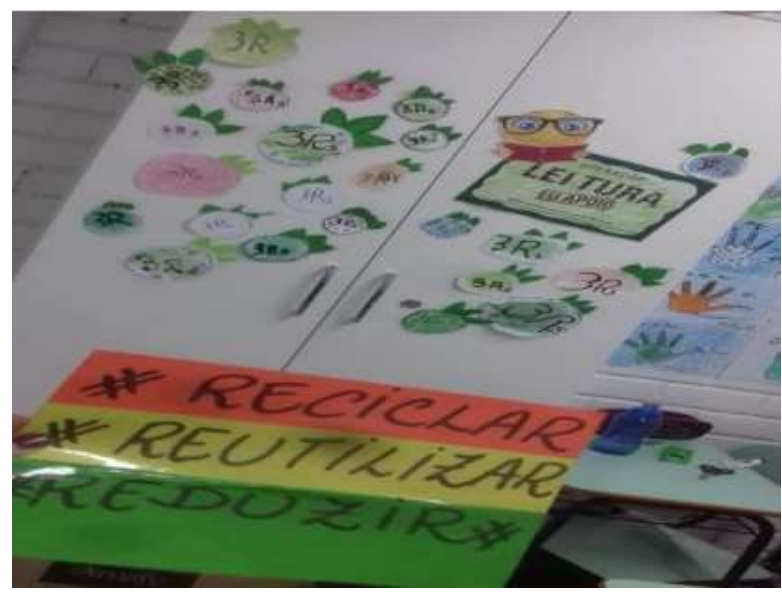

Fonte: Portfólio - Acervo Escola Batista.

Os alunos do Turno Integral (15 alunos) juntamente com a professora e a coordenadora, perceberam que nem todos os brinquedos, jogos e materiais escolares estavam sendo usados. Então, resolveram selecionar alguns para 
doação. As crianças ficaram motivadas com a arrecadação e ao mesmo tempo sensibilizadas ao perceber que outras crianças possuem tantas necessidades. As professoras aproveitaram o momento tão pertinente para mediar a reflexão e transformar em um aprendizado rico e promissor.

Aspecto importante da aprendizagem socioemocional é o foco nos outros. Segundo Goleman (2018): "Esta é a base da empatia, compreender como o outro se sente e seu modo de pensar acerca do mundo, junto de habilidade social, cooperação e trabalho em equipe".

Figura 9 . HÁBITO 5: PROCURE PRIMEIRO COMPREENDER PARA DEPOIS SER COMPREENDIDO - Escuta, empatia, honestidade.

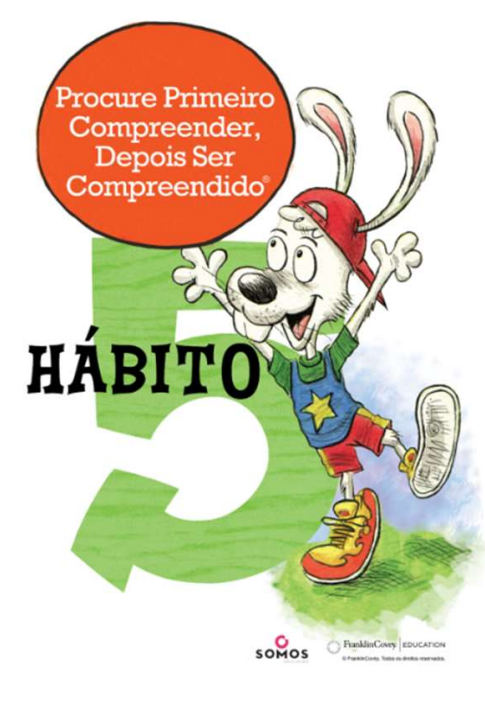

Fonte: OLEM Portfólio

Atividade: Bastão da Fala - As turmas do primeiro ano produziram o "Bastão da Fala". Baseado no hábito 5 do OLEM. "Procure primeiro compreender, depois ser compreendido" (figura 9), o bastão dá o direito de falar, enquanto os demais apenas escutam. Quando o aluno perceber que sua fala foi compreendida, passa o bastão para o próximo.

Atividade: Ouvindo com os olhos do coração: Com o objetivo de desenvolver o hábito 5 , "Procure primeiro compreender, depois ser compreendido", os alunos da turma 402 trouxeram de casa um objeto que tivesse um grande significado para cada um deles. Na sala de aula, explicaram 
para os demais colegas o porquê da escolha e qual a importância dele. Enquanto o colega falava, os demais escutavam.

Figura 10. HÁBITO 6: CRIE SINERGIA- Trabalho em equipe, resolução de problemas, criatividade.

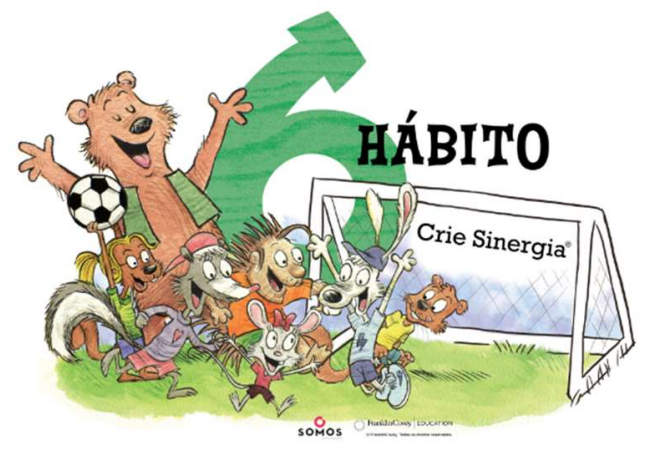

Fonte: Portfólio - OLEM

Atividade: A turma de ed. Infantil, nível B presenteou a Escola Batista com lindas flores plantadas pelos nossos pequenos. Começando com 0 objetivo de deixar a nossa escola mais bonita, os alunos plantaram e aprenderam sobre cuidado que devemos ter com as plantas.

Atividade: Sinergia na hora do conto (figura 10) - As duas turmas de segundo ano aprenderam sobre sinergia. E, para ilustrar melhor as professoras contaram a história "A cigarra e a formiga". Usando muita criatividade os alunos confeccionaram palitoches e um lindo formigueiro, ilustrando assim a aula. As professoras mediaram a atividade, instigando os alunos a perceberem a relação entre a cooperação que existe na construção de um formigueiro e, o trabalho em equipe que deve existir na sala de aula.

Os hábitos são desenvolvidos em diferentes conteúdos e temáticas das salas de aula, pois integram a rotina diária dos educandos. Ao trabalhar o hábito 6, "crie sinergia", as turmas de terceiro ano aprendem sobre a formação de frases, com uma brincadeira bem divertida, que consiste em "desembaralhar" as palavras e formar frases. 
Figura 11. Dinâmica: qual é a frase?
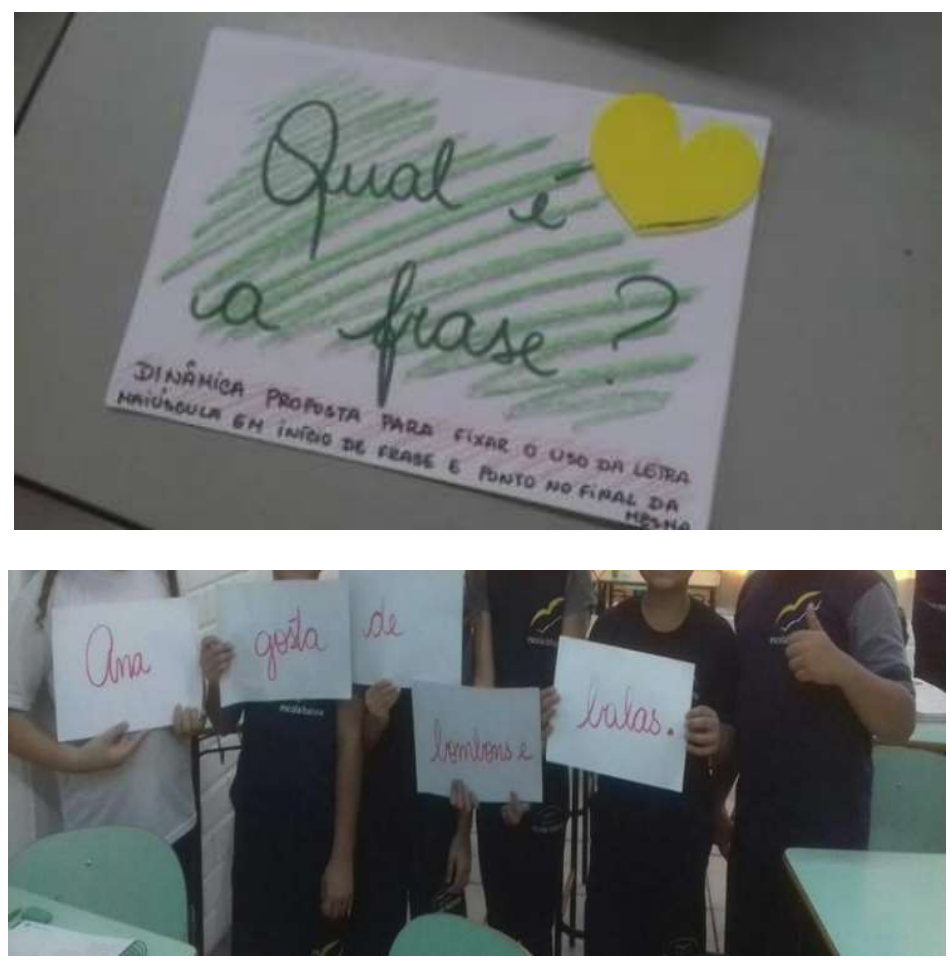

Fonte: Portfólio- Acervo-Escola Batista.

Figura 12. HÁBITO 7: AFINE OS INSTRUMENTOS - Corpo, Mente, Cérebro e alma

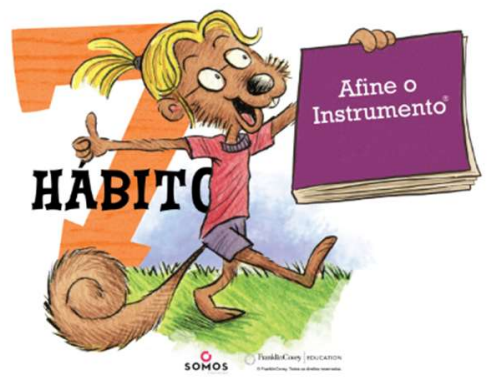

Fonte: Portfólio- OLEM

No hábito 7, "afine os instrumentos" (figura 12), os alunos participam de momentos que deixam corpo, mente e espírito alinhados e saudáveis. Para isso, são oferecidas atividades mais lúdicas e que busquem enfatizar as relações intra e interpessoais, como piqueniques, hora do conto, cinema, entre outras propostas.

Além das atividades em sala de aula, a escola promove eventos que possibilitem aos alunos apresentarem seus conhecimentos, como a Feira 
Pedagógica, Noite da Liderança, Chá para os avós, Festa de Inverno, entre outros. As famílias são engajadas neste processo de formação dos líderes. Os responsáveis participam de ações e contribuem trazendo seu conhecimento, experiência e vivências.

Figura 13. Atividade: Tempestade de Ideias

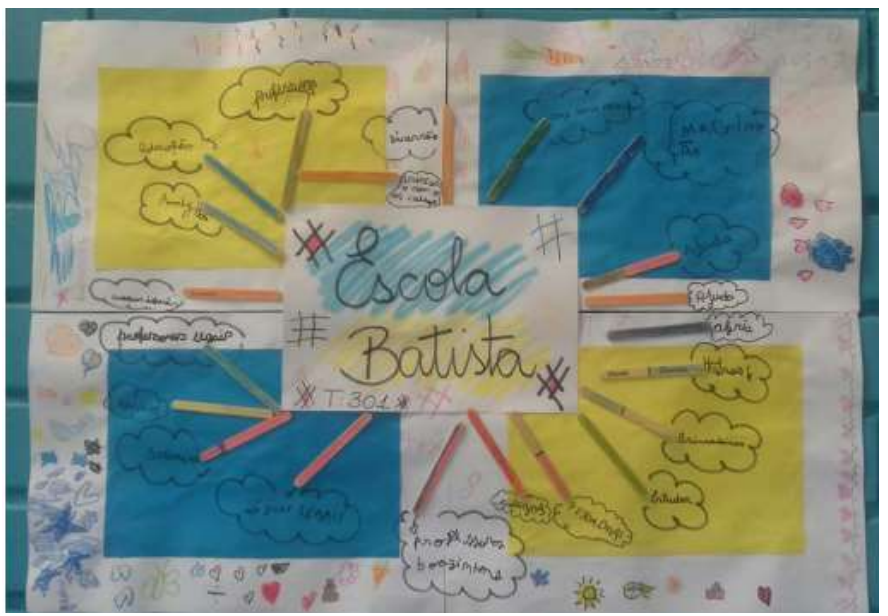

Fonte: Portfólio- Acervo Escola Batista.

\section{Considerações finais}

Partindo das colocações acima citadas, e de autores que já vem abordando este tema a bastante tempo, podemos perceber a necessidade atual de mais programas educacionais e de instituições escolares envolvidas no processo ensino aprendizagem, contribuindo assim, para uma educação humanizada. Exigindo assim uma preparação mais diferenciada, uma gestão participativa e inovadora, que não perceba o indivíduo como um mero aluno, objeto de trabalho, e sim o aluno como um ser humano, objeto da vida.

As escolas precisam estar atentas para esta nova tendência que vem sendo constatada, assim como também os próprios educadores necessitam desta adaptação, desta busca por um sistema de ensino mais efetivo e na construção da cidadania, preparando, de fato o educando não só para um futuro profissional promissor, e sim para a vida e suas relações, de uma maneira geral. Não podendo deixar de citar que as duas coisas estão diretamente ligadas. Uma educação realmente de qualidade só pode ser fruto de uma educação humanizada. 


\section{Referências}

ABED, Anita. O desenvolvimento das habilidades socioemocionais como caminho para a aprendizagem e o sucesso escolar de alunos da educação básica. São Paulo: UNESCO/MEC, 2014.

AFONSO, P. Dilemas da Liderança, Lisboa: Escolar Editora. 2011.

BENTO, A.; RIBEIRO, M.Y TELLES, C. Estilos de liderança nas organizações escolares do $1^{\circ}$. Ciclo da Região Autônoma da Madeira. In IV Simpósio sobre Organização e Gestão Escolar: A emergência do Diretor da Escola: Questões Políticas e Organizacionais. Aveiro: Universidade de Aveiro. 2010.

BRUENING, P. A história, os pilares e os objetivos da educação socioemocional. Educação pelo Brasil- Revista Educação Pámela Bruening ed 207. 2018.

FREIRE, P. Pedagogia do Oprimido. 31.ed. Rio de Janeiro: Paz e Terra, 2009.

GAMA, Maria Clara S. Salgado. A Teoria das Inteligências e suas implicações para Educação. 1998. Disponível em: http://www.homemdemello.com.br/psicologia/intelmult.html.

GARDNER, H. Estruturas da Mente- A Teoria das Inteligências Múltiplas. $1^{\circ}$ ed., Porto Alegre: Artes Médicas, 1994.

GOLEMAN, Daniel. Empatia e Liderança- Instituto VOCÊ. São Paulo, 2018.

OLEM. Pesquisa de Satisfação (pais, professores e mantenedora). 2018.

VILLAS BOAS, Benigna Maria de Freitas. Portfólio, avaliação e trabalho pedagógico. Campinas: Papirus, 2001.

\section{Sobre os Autores}

\section{Claudia Maria Sebalhos Lopes}

sebalhosclaudia@gmail.com

Possui Graduação em Educação Artística - Licenciatura Plena pela Universidade Federal de Santa Maria - UFSM, Graduação em Desenho Licenciatura Plena pela Universidade Federal de Santa Maria UFSM.Especialização em Pré-escola escola e Gestão Escolar pela antiga FICatual Universidade Franciscana (UFN). Atualmente é diretora pedagógica na escola Batista Santa Maria-RS.

\section{Janaína Pereira Pretto Carlesso}

janapcarlesso@yahoo.com.br

Possui graduação em Psicologia pela UNIFRA atual (UFN); Especialista em Educação Especial: Altas Habilidades/Superdotação pela (UFSM); Mestre em 
Distúrbios da Comunicação Humana pela (UFSM); Doutora em Educação em Ciências: Química da Vida e Saúde pela (UFSM). Na Universidade Franciscana (UFN) atua como professora adjunta no curso de graduação em Psicologia e no Mestrado em Ensino de Humanidades e Linguagens (MEHL). 